\title{
Prevalence and correlates of cigarette smoking among adolescents in Malawi: results from the Global Youth Tobacco Survey 2005
}

\author{
A.S. MUULA ${ }^{1,4}$, S. SIZIYA ${ }^{2 *}$ and E. RUDATSIKIRA ${ }^{3}$ \\ ${ }^{1}$ Department of Community Health, University of Malawi, College of Medicine, Blantyre, Malawi \\ ${ }^{2}$ Department of Community Medicine, University of Zambia, School of Medicine, University Teaching Hospital \\ Grounds, P.O. Box 50110, Lusaka, Zambia \\ ${ }^{3}$ Department of Global Health, Loma Linda University, School of Public Health, Loma Linda, California, \\ United States of America \\ ${ }^{4}$ Department of Epidemiology and Biostatistics, Loma Linda University, School of Public Health, Loma Linda, \\ California, United States of America
}

\begin{abstract}
The majority of adults who smoke cigarettes initiated the habit when they were adolescents or young adults. While rates of smoking and associated factors are known among 13-15 year olds in Malawi, correlates of cigarette smoking among adolescents in a national representative sample in Malawi have not been studied. We, therefore, carried out this study to estimate the prevalence of current smoking and determine its correlates in a nationally representative sample of in-school adolescents in Malawi. An analysis of the Malawi Global Youth Tobacco Survey (GYTS) 2005 was conducted. Using logistic regression analysis, we estimated the association between current cigarette smoking and potential explanatory variables. Overall, $2.5 \%$ of adolescents $(3.2 \%$ among males, and $1.8 \%$ among females) were current cigarette smokers. Smoking among parents was $9.6 \%$ with no significant difference between males and females $(10.3 \%$ versus $10.1 \%)$. Stronger associations with smoking were observed for friends smoking status ( $\mathrm{AOR}=3.07,95 \% \mathrm{CI} 2.99,3.16$ ), receiving pocket money (AOR $=3.06,95 \% \mathrm{CI}$ $2.98,3.14$ ), and perception that smoking increases body weight (AOR $=2.98,95 \% \mathrm{CI} 2.81,3.16$ ). Students who thought that cigarette smoking is harmful to health were $56 \%(\mathrm{AOR}=0.44,95 \% \mathrm{CI} 0.43,0.45)$ less likely to smoke than students who thought otherwise. Despite being the world's second leading grower of tobacco, the prevalence of cigarette smoking among adolescent is lower than has been reported elsewhere.
\end{abstract}

Key words: in-school adolescent, cigarette smoking, Malawi

\section{Introduction}

Tobacco is a leading cause of preventable non-communicable deaths. Mathers and Loncar (2006) projected the total tobacco-attributable deaths to rise from 5.4 million in 2005 to 6.4 million in 2015. Furthermore, tobacco was projected to kill 50\% more people in 2015 than HIV/AIDS, and to be responsible for $10 \%$ of all deaths globally.

Recently, Pampel (2005) using data from the Malawi Demographic and Health Survey of 2000, reported the prevalence of cigarette smoking at $16-18 \%$ for men and 1\% for women. Muula and Mpabulungi (2007)and Muula (2007) have reported the prevalence of current cigarette smoking among in-school adolescents at $6.2 \%$ in Lilongwe and 3.0\% in Blantyre in Malawi using data obtained from the Global Youth Tobacco Survey (GYTS) of 2001. Before the 2005 Malawi GYTS, there was paucity of data on a national representative sample of adolescents in Malawi. Following the 2005 survey, a fact sheet (CDC, 2005) has been published outlining rates of a limited list of tobacco use and associated factors. However, the possible associations of any explanatory variables to cigarette smoking have not been reported at a national level.

The majority of adult smokers initiated the habit as adolescents or young adults. This therefore makes the monitoring and prevention of adolescent smokers a critical public health exercise. Our understanding of adolescent smoking is enriched when we also explore the socio-demographic variables that are associated with smoking at both the personal and the societal level. We therefore carried out this study to estimate the prevalence of current smoking and associated variables in a nationally representative sample of in-school adolescents in Malawi. We also assessed associations between relevant explanatory variables and current cigarette smoking among the adolescents.

\footnotetext{
* Correspondence: Prof. Seter Siziya; E-mail: ssiziya@yahoo.com
} 


\section{Materials and Methods}

This study was based on a secondary analysis of data from the 2005 Malawi Global Youth Tobacco Survey. A comprehensive description of the GYTS purpose and methodology has been reported elsewhere (Warren et al., 2008). In brief however, the GYTS uses a questionnaire survey, recruits in-school adolescents from classes and the majority of students are aged between $13-15$ years. A two-stage clustered sampling approach is used in which the primary sampling units are schools. In the second stage of sampling, classes within the school are randomly selected. All students within the selected classes are eligible to participate in the study, regardless of their actual ages. However, students are free not to participate although identified as eligible for participation.

Study participants self-complete a questionnaire that has standard "core" questions, and a few other country-specific questions that are included by the specific country team. The core questions enable meaningful comparisons on responses between countries. Completion of the questionnaire is estimated to take about 40 minutes, and is done within a class session. There is no recording of student names or any person identifiers on the questionnaire. Questions are asked to collect information on the following variables: age, history of having ever smoked, sex, current smoking status, parental smoking, having friends who smoked, exposure to environmental tobacco smoke and tobacco advertisements, perception that smoking is harmful to health and amount of pocket money usually received per month.

In the Malawi GYTS, permission to conduct the study was obtained from the Ministry of Education. Completed questionnaires were scanned by computer and a data file was generated in Access. Overall response rate was $92.5 \%$. As per GYTS methodology, current cigarette smoking was defined as having smoked even a single puff of cigarette within the last 30 days preceding the survey (Warren et al., 2000).

Data were analyzed using SPSS software version 14.0 (Chicago, Illinois, United States). To assess associations between variables that were identified from the literature as possibly associated with current cigarette smoking, logistic regression analysis was conducted both at bivariate and multivariate level (Rudatsikira et al., 2008; Siziya et al., 2007). Backward logistic regression analysis was conducted to identify variables that are independently associated with smoking. Associations of cigarette advertisement or promotion factors with the outcome were adjusted for age and sex in addition to the other factors in the model. Messages against cigarette smoking were also adjusted for age and sex in addition to factors in the model. We report crude odds ratios (OR) and adjusted odds ratios (AOR) together with their 95\% confidence intervals (CI).

\section{Results}

\section{Sample description}

A total of 5135 students participated in the Malawi GYTS 2005. However, data on sex were available for 5119 students of whom $46.0 \%$ were male, and $54.0 \%$ were female students. About a third (32.0\%) of the students was aged 13 years. The proportions of participants whose parents and friends smoked were $10.3 \%$ and $15.5 \%$, respectively. The overall prevalence of current smoking was $2.5 \%$ (1.8\% among females, and $3.2 \%$ among males). The majority $(86.0 \%)$ of the students felt that smoking makes one lose weight. One in five (19.5\%) of the students recently received pocket money. Distributions of these factors by sex are shown in Table 1. 
Table 1: Social demographic description of the study participants in the Malawi GYTS 2005

\begin{tabular}{|c|c|c|c|c|}
\hline Factor & Response & $\begin{array}{l}\text { Total } \\
\mathbf{n}^{*}(\%)^{* *}\end{array}$ & $\begin{array}{l}\text { Male } \\
\mathbf{n}^{*}(\%)^{* *}\end{array}$ & $\begin{array}{l}\text { Female } \\
\text { n* }(\%)^{* *}\end{array}$ \\
\hline \multirow[t]{4}{*}{ Age } & $\leq 12$ & $1591(32.0)$ & 679 (31.1) & $912(33.0)$ \\
\hline & 13 & $1171(20.7)$ & $480(18.0)$ & $691(23.4)$ \\
\hline & 14 & 1098 (21.3) & $471(19.4)$ & $625(23.1)$ \\
\hline & $15+$ & $1253(26.0)$ & 724 (31.5) & 527 (20.5) \\
\hline \multirow{2}{*}{ Sex } & Male & 2357 (49.9) & - & - \\
\hline & Female & $2762(50.1)$ & - & - \\
\hline \multirow{2}{*}{ Parents smoked } & Yes & $474(9.6)$ & $232(10.3)$ & $241(10.1)$ \\
\hline & No & 4466 (90.4) & 2041 (89.7) & 2411 (89.9) \\
\hline \multirow{2}{*}{ Friends smoked } & Yes & $761(15.5)$ & $452(20.0)$ & $306(11.0)$ \\
\hline & No & 4307 (84.5) & $1876(80.0)$ & $2419(89.0)$ \\
\hline \multirow{2}{*}{$\begin{array}{l}\text { Received pocket } \\
\text { money }\end{array}$} & Yes & 1045 (19.5) & 480 (19.9) & 561 (18.9) \\
\hline & No & 4058 (80.5) & $1862(80.1)$ & $2184(81.1)$ \\
\hline \multirow{3}{*}{$\begin{array}{l}\text { Changes in body } \\
\text { weight due to smoking }\end{array}$} & $\begin{array}{l}\text { Gain } \\
\text { weight }\end{array}$ & 199 (3.9) & $99(4.4)$ & $100(3.5)$ \\
\hline & Lose weight & 4089 (81.7) & 1835 (78.8) & 2243 (83.3) \\
\hline & $\begin{array}{l}\text { Weight un- } \\
\text { changed }\end{array}$ & $778(15.4)$ & $393(16.8)$ & $381(13.2)$ \\
\hline
\end{tabular}

Overall, a third (31.8\% and $30.8 \%)$ of the respondents had seen actors smoking on television (TV), video or movies, and saw cigarette brand names when watching sports events or other programmes on TV, respectively. About half $(54.2 \%$ of the students had heard about cigarette brand names on radio, $53.2 \%$ had seen advertisements for cigarette on billboards, and $50.3 \%$ had seen advertisements for cigarettes in newspapers or magazines) were subjected to smoking advertisements through the media. About a quarter $(26.0 \%)$ of the students had seen advertisements for cigarettes at sports events, fairs, concerts, or community events (Table 2). 
Table 2: Prevalence of exposure to pro-smoking advertisements stratified by sex among study participants in the Malawi GYTS 2005

\begin{tabular}{|c|c|c|c|c|}
\hline Factor & Response & $\begin{array}{l}\text { Total } \\
\text { n* }(\%)^{* *}\end{array}$ & $\begin{array}{l}\text { Male } \\
\mathrm{n}^{*}(\%)^{* *}\end{array}$ & $\begin{array}{l}\text { Female } \\
\mathrm{n} *(\%)^{* *}\end{array}$ \\
\hline \multirow[t]{3}{*}{ Seen actors smoking on TV, video, or movies } & Yes & $1820(35.9)$ & $935(34.9)$ & $882(28.8)$ \\
\hline & No & $1067(21.1)$ & $417(21.4)$ & $647(25.1)$ \\
\hline & $\begin{array}{l}\text { Did not watch } \\
\text { TV }\end{array}$ & $2177(43.0)$ & $967(43.7)$ & $1202(46.1)$ \\
\hline \multirow[t]{2}{*}{ Had something with a cigarette logo on it } & Yes & $1133(22.3)$ & $563(23.6)$ & $564(21.1)$ \\
\hline & No & $3872(77.7)$ & $1730(76.4)$ & $2133(78.9)$ \\
\hline \multirow{3}{*}{$\begin{array}{l}\text { Saw cigarette brand names when watching sports } \\
\text { events or other programs on TV }\end{array}$} & Yes & $1734(30.3)$ & $820(31.2)$ & $907(29.2)$ \\
\hline & No & $1489(30.8)$ & $701(30.8)$ & $784(31.9)$ \\
\hline & Never watched & $1860(38.9)$ & $813(38.0)$ & $1042(38.9)$ \\
\hline \multirow[t]{3}{*}{ Heard cigarette brand names on radio } & Yes & $2877(54.2)$ & $1358(54.1)$ & $1511(54.4)$ \\
\hline & No & $1276(26.2)$ & $536(25.9)$ & $737(26.5)$ \\
\hline & $\begin{array}{l}\text { Never listened to } \\
\text { radio }\end{array}$ & 908 (19.6) & $429(20.0)$ & $475(19.1)$ \\
\hline \multirow[t]{2}{*}{ Seen advertisements for cigarettes on billboards } & Yes & $2787(53.2)$ & 1395 (57.1) & $1384(49.3)$ \\
\hline & No & $2198(46.8)$ & $880(42.9)$ & $1310(50.7)$ \\
\hline \multirow{2}{*}{$\begin{array}{l}\text { Seen advertisements for cigarettes in newspapers or } \\
\text { magazines }\end{array}$} & Yes & $2549(50.3)$ & $1278(54.9)$ & $1261(45.7)$ \\
\hline & No & $2358(49.7)$ & $967(45.1)$ & $1386(54.3)$ \\
\hline \multirow{3}{*}{$\begin{array}{l}\text { Seen advertisements for cigarettes at sports events, } \\
\text { fairs, concert or community events }\end{array}$} & Yes & $1337(26.0)$ & $664(28.3)$ & $665(23.6)$ \\
\hline & No & $2095(41.0)$ & $968(41.5)$ & $1122(40.5)$ \\
\hline & Never attended & $1636(33.0)$ & $691(30.2)$ & $942(35.9)$ \\
\hline \multirow[t]{2}{*}{ Attended concert sponsored by a cigarette brand } & Yes & $821(17.3)$ & $419(17.2)$ & $397(17.2)$ \\
\hline & No & $4254(82.7)$ & $1903(82.8)$ & $2340(82.8)$ \\
\hline \multirow[t]{2}{*}{ Cigarette representative ever offered a free cigarette } & Yes & $633(13.2)$ & $338(13.8)$ & $292(12.6)$ \\
\hline & No & $4390(86.8)$ & $1956(86.2)$ & $2422(87.4)$ \\
\hline $\begin{array}{l}\text { unweighted frequency } \\
* \text { weighted percent }\end{array}$ & & & & \\
\hline
\end{tabular}

Main sources of antismoking messages were media $(84.8 \%)$, youth groups $(73.1 \%)$, religious organizations $(73.0 \%)$, and family members $(71.8 \%)$. The majority of the respondents $(82.2 \%)$ thought cigarette smoking is harmful (Table 3). Between $22.3 \%$ and $54.2 \%$ of the participants had seen actors smoking on television, had an item with a tobacco brand logo, seen tobacco brands while watching games, heard about tobacco brand names on radio, seen tobacco advertisements in magazine and newspapers, and had seen adverts at sports or community events. About $17.3 \%$ and $13.2 \%$ had attended a concert promoted by a tobacco company and offered a free cigarette by a tobacco company representative respectively. 
Table 3: Prevalence of exposure to anti-smoking stratified by sex among study participants in the Malawi GYTS 2005

\begin{tabular}{|c|c|c|c|c|}
\hline & Response & Total & Male & Female \\
\hline Factor & & $\mathrm{n}^{*}(\%)^{* *}$ & $\mathrm{n} *(\%) * *$ & $\mathrm{n} *(\%) * *$ \\
\hline \multirow[t]{2}{*}{ Taught dangers of smoking } & Yes & $3097(61.7)$ & $1485(64.8)$ & $1601(58.5)$ \\
\hline & No & $1878(38.3)$ & $794(35.2)$ & $1080(41.5)$ \\
\hline \multirow[t]{2}{*}{ Seen or heard antismoking media messages } & Yes & $4290(84.9)$ & 1999 (86.2) & $2277(83.6)$ \\
\hline & No & $782(15.1)$ & $333(13.8)$ & $447(16.4)$ \\
\hline \multirow{3}{*}{$\begin{array}{l}\text { Seen antismoking messages at sports events, fairs, con- } \\
\text { cert, community gathering or social gathering }\end{array}$} & Yes & $2052(39.0)$ & $973(40.9)$ & $1071(37.0)$ \\
\hline & No & $799(14.3)$ & $344(14.3)$ & $452(14.4)$ \\
\hline & Never at- & $2226(46.7)$ & $1014(44.8)$ & $1207(48.6)$ \\
\hline \multirow{2}{*}{$\begin{array}{l}\text { Taught effects of smoking like yellowing of teeth, causes } \\
\text { wrinkles, or makes one smell badly }\end{array}$} & $\begin{array}{l}\text { tended } \\
\text { Yes }\end{array}$ & $3173(64.0)$ & $1517(67.0)$ & $1648(61.0)$ \\
\hline & No & $1898(36.0)$ & $804(33.0)$ & $1086(39.0)$ \\
\hline \multirow{2}{*}{$\begin{array}{l}\text { Heard from youth groups discouraging young people } \\
\text { from smoking }\end{array}$} & Yes & $3704(73.1)$ & $1694(73.5)$ & 1997 (72.6) \\
\hline & No & $1301(26.9)$ & $598(26.5)$ & $701(27.4)$ \\
\hline \multirow{2}{*}{$\begin{array}{l}\text { Health professionals explained why smoking is danger- } \\
\text { ous to health }\end{array}$} & Yes & $2956(58.8)$ & $1384(61.8)$ & $1561(55.7)$ \\
\hline & No & $2064(41.2)$ & $920(38.2)$ & $1140(44.3)$ \\
\hline \multirow{2}{*}{$\begin{array}{l}\text { Religious organizations discouraged young people from } \\
\text { smoking }\end{array}$} & Yes & $3626(73.0)$ & $1664(74.8)$ & $1951(71.1)$ \\
\hline & No & $1315(27.0)$ & $607(25.2)$ & $707(28.9)$ \\
\hline \multirow[t]{2}{*}{ Family members discussed harmful effects of smoking } & Yes & $3740(71.8)$ & $1739(73.4)$ & $1987(70.1)$ \\
\hline & No & $1326(28.2)$ & $595(26.6)$ & $729(29.9)$ \\
\hline \multirow[t]{2}{*}{ Thought cigarette smoking is harmful to health } & Yes & $4208(82.2)$ & $1888(81.8)$ & $2307(82.5)$ \\
\hline & No & $776(17.8)$ & $404(18.2)$ & $371(17.5)$ \\
\hline
\end{tabular}

Social, demographic, and economic correlates for current smoking status are summarised in Table 4. Stronger associations with current smoking status were observed for friends smoking status $(\mathrm{AOR}=3.07,95 \% \mathrm{CI} 2.99$,
$3.16)$, receiving pocket money $(\mathrm{AOR}=3.06,95 \% \mathrm{CI}$ $2.98,3.14)$, and perception that smoking increases body weight $(\mathrm{AOR}=2.98,95 \%$ CI 2.81, 3.16). 
Table 4: Associations of social, demographic and economic factors with current cigarette smoking among study participants in the Malawi GYTS 2005

\begin{tabular}{|c|c|c|}
\hline Factor & $\begin{array}{l}\text { Crude odds ratio } \\
\text { OR }(95 \% \mathrm{CI})\end{array}$ & $\begin{array}{l}\text { Adjusted odds ratio } \\
\text { AOR }(95 \% \mathrm{CI})\end{array}$ \\
\hline \multicolumn{3}{|l|}{ Age } \\
\hline$\leq 12$ & $0.93(0.90,0.96)$ & $1.03(0.98,1.07)$ \\
\hline 13 & $0.85(0.82,0.89)$ & $0.92(0.87,0.97)$ \\
\hline 14 & $0.91(0.88,0.95)$ & $0.80(0.76,0.84)$ \\
\hline $15+$ & 1 & 1 \\
\hline \multicolumn{3}{|l|}{ Sex } \\
\hline Male & $1.31(1.28,1.33)$ & $1.07(1.04,1.10)$ \\
\hline Female & 1 & 1 \\
\hline \multicolumn{3}{|l|}{ Parents smoked } \\
\hline Yes & $2.33(2.28,2.39)$ & $1.70(1.65,1.75)$ \\
\hline No & 1 & 1 \\
\hline \multicolumn{3}{|l|}{ Friends smoked } \\
\hline Yes & $3.93(3.84,4.02)$ & $3.07(2.99,3.16)$ \\
\hline No & 1 & 1 \\
\hline \multicolumn{3}{|l|}{ Received pocket money } \\
\hline Yes & $3.97(3.87,4.06)$ & $3.06(2.98,3.14)$ \\
\hline No & 1 & \\
\hline \multicolumn{3}{|c|}{ Changes in body weight due to smoking } \\
\hline Gain weight & $2.94(2.81,3.07)$ & $2.98(2.81,3.16)$ \\
\hline Lose weight & $0.49(0.48,0.51)$ & $0.57(0.55,0.60)$ \\
\hline Weight unchanged & 1 & 1 \\
\hline
\end{tabular}

AOR $(95 \% \mathrm{CI})$ are adjusted for all the factors in the table

All the factors in Table 5 were positively significantly associated with current smoking, except for the factor 'seeing advertisements in newspapers or magazines'. Students who had seen advertisements for cigarettes in newspapers or magazines were $4 \%(\mathrm{AOR}=0.96,95 \% \mathrm{CI}$ $0.93,0.99$ ) less likely to have been current smokers. Respondents who had seen actors smoking on TV
(AOR $=1.87,95 \% \mathrm{CI} 1.80,1.95)$, those who had heard of cigarette brand names on radio $(\mathrm{AOR}=1.64,95 \% \mathrm{CI}$ $1.56,1.73)$, and those who were offered free cigarettes by a cigarette representative were more likely to smoke cigarettes than those who never watched TV, never listened to radio, and never offered free cigarettes from cigarette representatives. 
Table 5: Associations of advertisement or promotion factors with current cigarette smoking among study participants in the Malawi GYTS 2005

\begin{tabular}{|c|c|c|c|}
\hline Factor & Response & $\begin{array}{l}\text { Crude odds } \\
\text { ratio } \\
(95 \% \mathrm{CI})\end{array}$ & $\begin{array}{l}\text { Adjusted odds } \\
\text { ratio }(95 \% \mathrm{CI})\end{array}$ \\
\hline \multirow{3}{*}{$\begin{array}{l}\text { Seen actors smoking on TV, video, or } \\
\text { movies }\end{array}$} & Yes & $2.11(2.05,2.18)$ & $1.87(1.80,1.95)$ \\
\hline & No & $0.80(0.77,0.83)$ & $1.24(1.18,1.30)$ \\
\hline & Did not watch TV & 1 & 1 \\
\hline \multirow[t]{2}{*}{ Had something with a cigarette logo on it } & Yes & $1.53(1.50,1.57)$ & $1.31(1.27,1.35)$ \\
\hline & No & 1 & 1 \\
\hline \multirow{3}{*}{$\begin{array}{l}\text { Saw cigarette brand names when watching } \\
\text { sports events or other programs on TV }\end{array}$} & Yes & $1.76(1.71,1.81)$ & $1.13(1.09,1.18)$ \\
\hline & No & $0.85(0.82,0.88)$ & $1.35(1.30,1.42)$ \\
\hline & Never watched TV & 1 & 1 \\
\hline \multirow[t]{3}{*}{ Heard cigarette brand names on radio } & Yes & $1.39(1.35,1.43)$ & $1.64(1.56,1.73)$ \\
\hline & No & $0.63(0.60,0.66)$ & $0.36(0.33,0.39)$ \\
\hline & Never listened & 1 & 1 \\
\hline \multirow{2}{*}{$\begin{array}{l}\text { Seen advertisements for cigarettes on } \\
\text { billboards }\end{array}$} & Yes & $1.51(1.48,1.55)$ & $1.49(1.44,1.55)$ \\
\hline & No & 1 & 1 \\
\hline \multirow{2}{*}{$\begin{array}{l}\text { Seen advertisements for cigarettes in } \\
\text { newspapers or magazines }\end{array}$} & Yes & $1.37(1.34,1.40)$ & $0.96(0.93,0.99)$ \\
\hline & No & 1 & 1 \\
\hline \multirow{3}{*}{$\begin{array}{l}\text { Seen advertisements for cigarettes at sports } \\
\text { events, fairs, concert or community events }\end{array}$} & Yes & $2.31(2.25,2.38)$ & $1.25(1.20,1.29)$ \\
\hline & No & $0.53(0.51,0.55)$ & $0.86(0.82,0.90)$ \\
\hline & Never attended & 1 & 1 \\
\hline \multirow{2}{*}{$\begin{array}{l}\text { Attended concert sponsored by a cigarette } \\
\text { brand }\end{array}$} & Yes & $1.95(1.91,1.99)$ & $1.29(1.25,1.33)$ \\
\hline & No & 1 & 1 \\
\hline \multirow{2}{*}{$\begin{array}{l}\text { Had a free offer from Cigarette } \\
\text { representative }\end{array}$} & Yes & $2.08(2.04,2.13)$ & $1.73(1.68,1.79)$ \\
\hline & No & 1 & 1 \\
\hline
\end{tabular}

AOR $(95 \% \mathrm{CI})$ are adjusted for age and sex in addition to all the factors in the table

We found that being taught dangers of smoking $(\mathrm{AOR}=1.06,95 \% \mathrm{CI} 1.02,1.09)$, seeing antismoking messages at sports events, fairs, concerts, community gathering, or social events (AOR=1.60, 95\%CI 1.54 , 1.66), and religious organizations discouraging young people from smoking (AOR $=1.19,95 \% \mathrm{CI} 1.15,1.23$ ) were positively associated with current cigarette smoking. The rest of the factors in Table 6 were negatively associated with current cigarette smoking. While explanation by health workers that smoking is dangerous was positively associated with current cigarette smoking in a bivariate analysis, this factor was not significantly associated with current cigarette smoking in a multivariate analysis. The largest magnitude of association was observed for the factor 'thinking that cigarette smoking is harmful to health'. Students who thought that cigarette smoking is harmful to health were $56 \%$ ( $\mathrm{AOR}=0.44$, $95 \%$ CI $0.43,0.45)$ less likely to smoke than those who thought otherwise. 
Table 6: Associations of antismoking messages with current smoking status among study participants in the Malawi GYTS 2005

\begin{tabular}{|c|c|c|c|}
\hline Factor & Response & $\begin{array}{l}\text { Crude odds } \\
\text { ratio } \\
(95 \% \mathrm{CI})\end{array}$ & $\begin{array}{l}\text { Adjusted odds } \\
\text { ratio }(95 \% \mathrm{CI})\end{array}$ \\
\hline \multirow[t]{2}{*}{ Taught dangers of smoking } & Yes & $0.77(0.75,0.79)$ & $1.06(1.02,1.09)$ \\
\hline & No & 1 & 1 \\
\hline \multirow[t]{2}{*}{ Seen or heard antismoking media messages } & Yes & $0.89(0.86,0.91)$ & $0.89(0.86,0.93)$ \\
\hline & No & 1 & 1 \\
\hline \multirow{3}{*}{$\begin{array}{l}\text { Seen antismoking messages at sports events, } \\
\text { fairs, concert, community gathering or social } \\
\text { gathering }\end{array}$} & Yes & $1.52(1.47,1.56)$ & $1.60(1.54,1.66)$ \\
\hline & No & $0.89(0.85,0.93)$ & $1.06(1.01,1.12)$ \\
\hline & $\begin{array}{l}\text { Never attended } \\
\text { social gatherings }\end{array}$ & 1 & 1 \\
\hline \multirow{2}{*}{$\begin{array}{l}\text { Taught effects of smoking like yellowing of } \\
\text { teeth, causes wrinkles, or makes one smell } \\
\text { badly }\end{array}$} & Yes & $0.76(0.74,0.78)$ & $0.81(0.79,0.84)$ \\
\hline & No & 1 & 1 \\
\hline \multirow{2}{*}{$\begin{array}{l}\text { Heard from youth groups discouraging young } \\
\text { people from smoking }\end{array}$} & Yes & $0.64(0.62,0.65)$ & $0.66(0.64,0.68)$ \\
\hline & No & 1 & 1 \\
\hline \multirow{2}{*}{$\begin{array}{l}\text { Health professionals explained why smoking } \\
\text { is dangerous to health }\end{array}$} & Yes & $1.07(1.04,1.09)$ & - \\
\hline & No & 1 & \\
\hline \multirow{2}{*}{$\begin{array}{l}\text { Religious organizations discouraged young } \\
\text { people from smoking }\end{array}$} & Yes & $0.88(0.86,0.90)$ & $1.19(1.15,1.23)$ \\
\hline & No & 1 & 1 \\
\hline \multirow{2}{*}{$\begin{array}{l}\text { Family members discussed harmful effects of } \\
\text { smoking }\end{array}$} & Yes & $0.88(0.86,0.90)$ & $0.94(0.91,0.97)$ \\
\hline & No & 1 & 1 \\
\hline \multirow{2}{*}{$\begin{array}{l}\text { Thought cigarette smoking is harmful to } \\
\text { health }\end{array}$} & Yes & $0.48(0.47,0.49)$ & $0.44(0.43,0.45)$ \\
\hline & No & 1 & 1 \\
\hline
\end{tabular}

Adjusted Odds Ratio $(95 \% \mathrm{CI})$ are adjusted for age and sex in addition to all the factors in the table

\section{Discussion}

To our knowledge, the Malawi GYTS 2005 is the first ever nationally representative sample of in-school adolescents studied on tobacco use, including cigarette smoking. Previous surveys have been limited to specific geographic areas such Lilongwe and Blantyre (Muula, 2007; Mpabulungi \& Muula, 2007). The overall prevalence of current cigarette smoking was $2.5 \%$. The gender difference may be related to societal tolerance of smoking among males compared to females. Compared to the estimate obtained in the GYTS 2001 for Blantyre (3.0\%) and Lilongwe (6.2\%), the national prevalence is much lower. The reasons behind these differences are not known. However, we can suggest a few possibilities. Both studies in Blantyre and Lilongwe were conducted only in the urban areas of these districts. It is possible that smoking prevalence may be higher in urban commercial centres than the national estimates that also include rural areas. Secondly, it is possible that smoking prevalence has gone down. However, we do not have data for a national estimate for 2001 to verify if this assumption is correct. Nevertheless, between 2001 and 2005, there have been public health efforts, save for legislated changes, aimed to raise awareness among schoolchildren on the harmful effects of smoking. 
In the developed world, adolescents may be motivated to initiate smoking in order to lose weight, which is perceived as a desirable outcome in these settings. Bean et al. (2008) have reported that adolescent non-smokers believed that smoking would result in weight loss, while smokers believed that they would gain weight if they stopped smoking. However, Bentley et al. (2005) reported that heavier built bodies were desirable among women in Malawi, in contrast to leaner bodies in the United States. Whether adolescents in Malawi hold different or similar views as their American counterparts deserve further study.

The low prevalence of smoking is also reflected in a low smoking prevalence among parents of the study participants. Slama (2008) has reported smoking prevalence rates of $49 \%$ and $8 \%$ among men and women in low- and mid-income countries. Our estimates are much lower, especially for men (10.3\% for Malawi versus $49 \%$ globally), but higher for Malawian women $(10.1 \%)$ compared to the global estimates $(8 \%)$. It is possible that the Malawi estimates may in fact be underestimates as these (the estimates) were based on reports by smokers' children. Comparisons with data obtained when adults are surveyed need to be made with this caveat in mind.

Factors such as seeing actors smoking on television, having an item with a tobacco brand logo, seeing tobacco brands while watching games, heard about tobacco brand names on radio, seeing tobacco advertisements in magazine and newspapers, and having seen adverts at sports or community events have been reported in previous studies to be associated with smoking among adolescents (Laugesen et al., 2007; Scragg \& Laugesen, 2007; Siziya et al., 2007). Exposure to anti-tobacco initiatives such as being taught the dangers of smoking, having seen anti-smoking messages, discussed with family members on smoking and heard anti-smoking messages on the media may have led to the majority $(81.8 \%)$ believing that smoking is harmful to health. In general, being exposed to pro-tobacco media was associated with increased likelihood of being a smoker. This observation is in keeping with the Social Cognitive Theory (Bandura, 2001; Glanz et al., 2002). The theory proposes that environment, people, and behaviour are constantly influencing each other in influencing behaviour. Of relevance to adolescent smoking is the recognition that the social environment that the adolescent is exposed to may influence when he or she initiates and/or maintains smoking.

We note some unexpected findings regarding smoking and explanatory variables. We found that adolescents who reported exposure to anti-tobacco advertisements were more likely to be current cigarette smokers. Study participants who reported being taught the dangers of smoking, had heard religious groups discouraging smoking, seen anti-smoking messages at public events or social gathering, had a health professional discuss smoking with them were more likely to be smokers. We are unable to obtain reasons for these paradoxical associations. However, potential explanations can be suggested. It is possible that adolescents who were smokers were more likely to have a discussion about smoking with a health professional as part of usual clinical care or due to illnesses associated with smoking (e.g. asthma or chronic cough). Schools with high smoking prevalence among students may also be more likely to have lessons aimed at discouraging students from smoking. Another alternative explanation is that the anti-tobacco messages were yet to be effective.

Henriksen et al. (2006) have reported that tobacco industry sponsored anti-tobacco messages may not result in decreasing tobacco use. These authors have reported that anti-tobacco messages from tobacco firms were more effective in building corporate image rather than preventing smoking. In Malawi, anti-tobacco message are likely to come from tobacco firms on radio advertisements aimed to promote smoking.

Malawi is the second leading grower of tobacco and no other country in the world is economically dependent on tobacco as Malawi (Davies, 2003; Otañez et al., 2007; Diao et al., 2002; FAO, 2003; Jaffe, 2003). However, it appears that such a leading role in tobacco farming has not been translated into the country being a large cigarette consumer.

The limitations of the GYTS methodology has been reported elsewhere (Siziya et al., 2008; Warren et al., 2008). Firstly, data was collected from a selfcompleted questionnaire. For the main outcome of the current analysis, students were asked: During the past 30 days (one month), on how many days did you smoke cigarettes? Students may have intentionally miss-reported. It is also possible that some students may have genuinely forgotten whether they had smoked within the past 30 days. Another limitation is the GYTS definition of current smoking, defined as having smoked, even a single puff within the last 30 days. It should be clear that some students who may have smoked a single puff might have never smoked again. As to how many of such students there were in our sample is not known. Nevertheless, if the proportion of students who experimented with a single puff was high, our estimates lead us to exaggerate the public health importance of adolescent smoking in Malawi. 
The GYTS methodology recruits study participants from schools. Our findings may not be applicable to out-of-school adolescents. Many secondary schoolage adolescents are not enrolled in school. As school attendance is not compulsory and the out-of-school adolescent population is large, the overall prevalence of smoking among adolescents in the country may be assessed if both in-school and out of school adolescents are sampled. Furthermore, the GYTS methodology administers the questionnaire only to those students who are available in school on the day the survey is conducted, and as such, the findings may not be representative of all age-eligible students. However, the response rate was relatively high $(84.3 \%)$ suggesting that most of the students who were eligible to participate did actually participate in the survey. In addition, the smoking status of the study participants was not validated by biomarkers such as salivary or urine cotinine. Even if these were used, they would have only been useful to determine the smoking status of students within the past few days. A student who had smoked for instance 29 days ago, may not exhibit biomarkers of smoking. Analysis of other bio-samples such as hair or finger nails for tobacco bi-products would also not distinguish between adolescents own smoking and environmental tobacco exposure.

In conclusion, we have estimated an overall prevalence of current cigarette smoking of $2.5 \%$ among in-school adolescents in Malawi, despite the country being the second leading grower of tobacco. This prevalence estimate is among the lowest in-school adolescents when compared to other estimates reported from similar settings.

\section{Acknowledgements}

We thank all the study participants for their involvement in the study. We are also grateful to the Centres for Disease Control and Prevention (CDC) for making the data from the Malawi GYTS available to us for analysis. The CDC had no influence regarding the analysis that we conducted, nor the decision to have these findings published.

Received 11 May 2008

Revised 12 June 2008

Accepted 13 June 2008

\section{References}

Bandura, A. (2001) Social cognitive theory: An agentive perspective. Annual Review of Psychology 52, 1-26.

Bean, M.K., Mitchell, K.S., Speizer, I.S., Wilson, D.B., Smith, B.N. \& Fries, E.A. (2008) Rural adolescent attitudes toward smoking and weight loss: relationship to smoking status. Nicotine Tobacco Research 10, 279-286.

Bentley, M.E., Corneli, A.L., Piwoz, E., Moses, A., Nkhoma, J., Tohill, B.C., Ahmed, Y., Adair, L., Jamieson, D.J. \& van der Horst, C. (2005) Perceptions of the role of maternal nutrition in HIV-positive breast-feeding women in Malawi. Journal of Nutrition 135, 945-949.

CDC (2005) Global Youth Tobacco Survey Malawi. Centres for Disease Control and Prevention. http://www.cdc.gov/tobacco/Global/GYTS/ factsheets/afro/2005/ malawi_factsheet.htm. Accessed 5 May 2008.

Davies, P. (2003) Malawi: addicted to the leaf. Tobacco Control 12, 91-93.

Diao, X., Robinson, S., Thomas, M. \& Wobst, P. (2002) Assessing impacts of declines in the world price of tobacco on China, Malawi, Turkey, and Zimbabwe. Washington, DC: International Food Policy Research Institute. http://www.ifpri. org/divs/tmd/dp/papers/tmdp91.pdf. Accessed 5 May 2008.

FAO (2003) Issues in The Global Tobacco Economy: Selected Case Studies. Rome: Food and Agriculture Organization of the United Nations, http://www.ftp.fao.org/ docrep/fao/006/y4997E/ y4997e01.pdf. Accessed 5 May 2008.

Glanz, K., Rimer, B.K. \& Lewis, F.M. (2002) Health Behaviour and Health Education. Theory, Research and Practice. San Francisco: Wiley \& Sons.

Henriksen, L., Dauphinee, A.L., Wang, Y. \& Fortmann, S.P. (2006) Industry sponsored anti-smoking ads and adolescent reactance: test of a boomerang effect. Tobacco Control 15, 13-18.

Jaffe, S. (2003) Malawi's Tobacco Sector: Standing on One Strong Leg is Better Than on None. Washington, DC: World Bank, 2003. http://www. worldbank.org/afr/wps/wp55.pdf. Accessed 5 May 2008.

Laugesen, M., Scragg, R., Wellman, R.J. \& DiFranza, J.R. (2007) Rated film viewing and adolescent smoking. Preventive Medicine 45, 454-459.

Mathers, C.D. \& Loncar, D. (2006) Projections of global 
mortality and burden of disease from 2002 to 2030. PLoS Medicine 3, e442.

Muula, A.S. \& Mpabulungi, L. (2007) Cigarette smoking prevalence among school-going adolescents in two African capital cities: Kampala Uganda and Lilongwe Malawi. African Health Sciences 7, 45-49.

Muula, A.S. (2007) Prevalence and determinants of cigarette smoking among adolescents in Blantyre City, Malawi. Tanzanian Health Research Bulletin 9, 48-51.

Otañez, M.G., Mamudu, H. \& Glantz, S.A. (2007) Global leaf companies control the tobacco market in Malawi. Tobacco Control 16, 261-269.

Pampel, F.C. (2005) Patterns of tobacco use in the early epidemic stages: Malawi and Zambia, 20002002. American Journal of Public Health 95, 1009-1015.

Rudatsikira, E., Dondog, J., Siziya, S. \& Muula, A.S. (2008) Prevalence and determinants of adolescent cigarette smoking in Mongolia. Singapore Medical Journal 49, 57-62.

Scragg, R. \& Laugesen, M. (2007) Influence of smoking by family and best friend on adolescent tobacco smoking: results from the 2002 New Zealand national survey of year 10 students. Australia and New Zealand Journal of Public Health 31, 217-223.
Siziya, S., Ntata, P.R., Rudatsikira, E., Makupe, C.M., Umar, E. \& Muula, A.S. (2007) Sex differences in prevalence rates and predictors of cigarette smoking among in-school adolescents in Kilimanjaro, Tanzania. Tanzania Health Research Bulletin 9, 190-195.

Siziya, S., Muula, A.S. \& Rudatsikira, E. (2008) Correlates of current cigarette smoking among school-going adolescents in Punjab, India: results from the Global Youth Tobacco Survey 2003. BMC International Health and Human Rights 8, 1.

Slama, K. (2008) Global perspective on tobacco control. Part I. The global state of the tobacco epidemic. International Journal of Tuberculosis and Lung Diseases 12, 3-7.

Warren, C.W., Jones, N.R., Peruga, A., Chauvin, J., Baptiste, J.P., Costa de Silva, V., el Awa, F., Tsouros, A., Rahman, K., Fishburn, B., Bettcher, D.W, Asma, S. \& Centres for Disease Control and Prevention (CDC) (2008) Global youth tobacco surveillance, 2000-2007. Morbidity and Mortality Weekly Reports Surveillance Summaries 57, 1-28.

Warren, C.W., Riley, L., Asma, S., Eriksen, M.P., Green, L., Blanton, C., Loo, C., Batchelor, S. \& Yach, D. (2000) Tobacco use by youth: a surveillance report from the Global Youth Tobacco Survey project. Bulletin of the World Health Organization 78, 868-876. 